\title{
Gestão macroeconômica e controles de capitais
}

Ronald Hillbrecht ${ }^{*}$

RESUMO - Esta nota discute as implicações da imposição de controles de capitais sobre variáveis macroeconômicas, tanto no que diz respeito a políticas de estabilização, quanto no que diz respeito a crescimento econômico de longo prazo. Vasta evidência empírica permite sugerir que, a despeito de seus custos microeconômicos e duvidosas vantagens macroeconômicas, existe um espaço, ainda que limitado, para que controles de capitais sejam úteis no alcance de determinados objetivos econômicos.

Palavras-chave: Globalização financeira. Fluxos de capitais. Políticas macroeconômicas. Crescimento econômico. Controles de capitais.

\section{INTRODUÇÃO}

Existe um intenso debate no mundo acadêmico e entre elaboradores de política no que diz respeito à desejabilidade de fluxos livres de capitais. De acordo com a teoria econômica convencional, fluxos de capitais melhoram a alocação global de recursos, pois o capital migraria de países desenvolvidos, onde a taxa marginal de retorno do capital seria mais baixa, para países em desenvolvimento e mercados emergentes, onde as taxas marginais de retorno seriam mais altas, refletindo sua escassez relativa. Desta forma, movimentos de capital para países de maior taxa marginal de retorno lhes seriam benéficos, pois poderiam financiar mais projetos de alta taxa de retorno e acelerar o crescimento econômico.

Entretanto, a experiência empírica parece divergir da teoria. De acordo com Davies e Drexler (2010), o Gráfico 1 abaixo apresenta evidências de “animal spirits”: em 1998-2002, quando a bolha dot-com produziu o crowding out de investimentos em mercados emergentes, e em 2001-2007 quando um volume crescente de poupança global buscou oportunidades rentáveis de investimento. Adicionalmente, o período 1997-2002 produziu uma reversão do fluxo de capitais privados (criando uma saída líquida de capitais) em países asiáticos em desenvolvimento, em decorrência da crise financeira da Ásia de 1997. A forte contração dos fluxos de capital para mercados emergentes e países em desenvolvimento, depois de alcançar um pico em 2007, por outro lado, não parece ter sido causada por uma súbita falta de oportunidades de investimento.

O objetivo desta nota é avaliar a ideia de imposição de controles de capitais para evitar

\footnotetext{
* Doutor em economia pela Universidade de Illinois em Urbana-Champaign. É professor adjunto do Departamento de Economia da Universidade Federal do Rio Grande do Sul. Endereço eletrônico: ottohill@ufrgs.br.
} 
que a elevada volatilidade de fluxos de capitais tenha desdobramentos negativos no que diz respeito a políticas de estabilização macroeconômica, sem no entanto prejudicar prospectos de maior crescimento econômico de longo prazo. A Seção 2 analisa as relações entre globalização financeira e desempenho macroeconômico, enquanto que a Seção 3 busca avaliar a eficácia de controles de capitais. Finalmente, a Seção 4 conclui.

GRÁFICO 1 - FLUXOS FINANCEIROS PRIVADOS LÍQUIDOS PARA MERCADOS EMERGENTES E PAÍSES EM DESENVOLVIMENTO

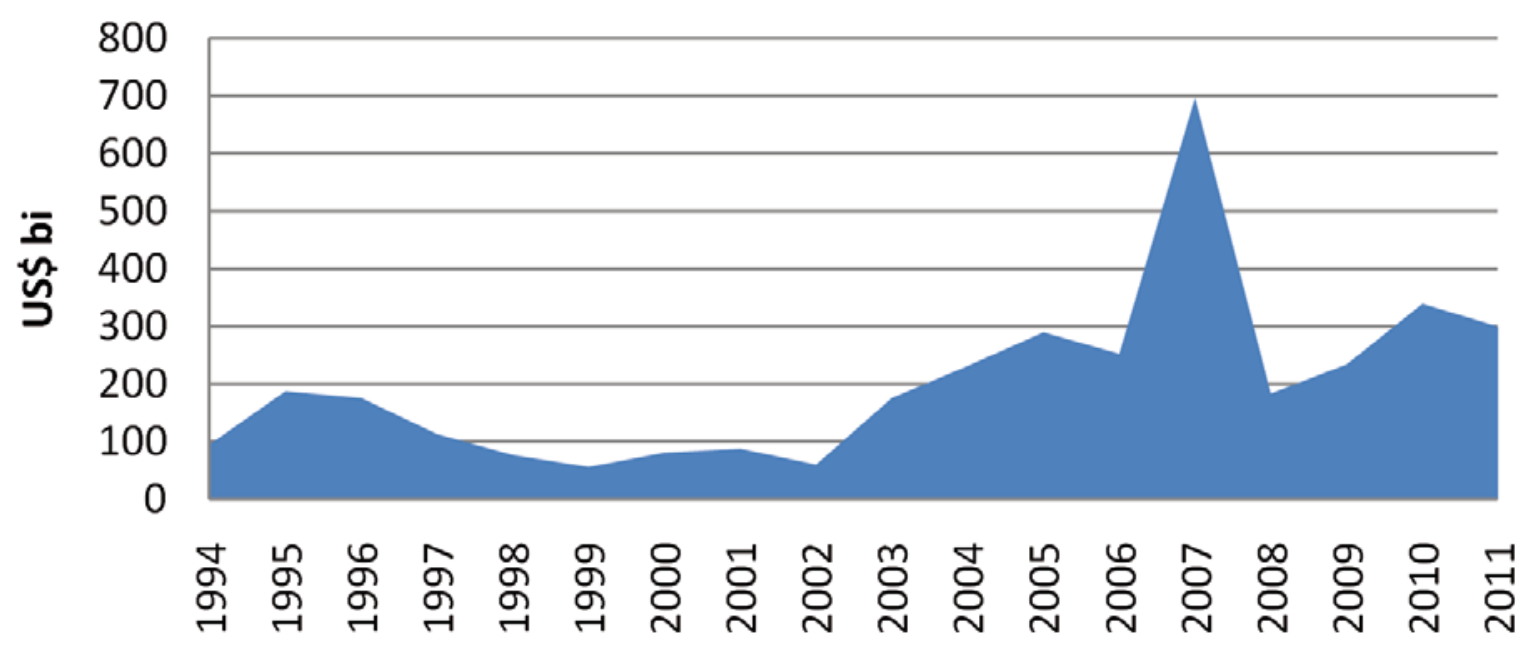

FONTE: IMF, World Economic Outlook, October 2010.

\section{GLOBALIZAÇÃO FINANCEIRA E PERFORMANCE MACROECONÔMICA}

Globalização financeira é um dos tópicos de pesquisa teórica e empírica mais importantes e controversos. Globalização financeira, nas formas de liberalização da conta capital e livre movimentação de capital, tem sido interpretada como um fator indutor de instabilidade e crise financeira ${ }^{1}$. Por outro lado, a maior abertura da conta capital pode ser vista como um passo necessário para que um país relativamente pobre em capital possa alcançar maior crescimento econômico, ao mesmo tempo em que produz maior estabilidade em países industrializados ${ }^{2}$. Kose, Prasad, Rogoff e Wei (2010), em resenha da literatura recente, sugerem que políticas econômicas que promovem o desenvolvimento do setor financeiro, qualidade institucional e abertura comercial, são importantes não apenas por si só, mas como também ajudam os países menos desenvolvidos a capturar os benefícios da globalização. Da mesma forma, políticas macroeconômicas consistentes parecem ser um importante pré-requisito para garantir que a globalização financeira seja benéfica para os estes países. Adicionalmente, Kose, Prasad, Rogoff

1 Ver, por exemplo, Stiglitz (2002) e Rodrick (1998).

2 Ver, por exemplo, Summers (2000) e Fischer (1998). 
e Wei (2010) também sugerem que dependência excessiva de regimes de câmbio fixo tem sido um fator dos mais importantes para a proliferação de crises financeiras em países de mercados emergentes nos últimos quinze anos. Desta forma, a adoção de um regime de câmbio flutuante contribui para a redução dos riscos que os países incorrem ao se tornarem financeiramente mais integrados. Finalmente, Kose, Prasad, Rogoff e Wei (2010) também sugerem que países que sistematicamente têm problemas com endividamento público podem se beneficiar mais da globalização financeira se seus governos tomarem medidas para evitar acumulação excessiva de dívida pública.

Teoricamente, os impactos esperados da globalização financeira sobre o crescimento econômico podem ser divididos entre impactos diretos e indiretos. Os impactos diretos decorrem do aumento do estoque de capital em países relativamente pobres em capital, impactos estes provenientes do influxo de capital em busca de taxas de retorno mais elevadas. Este influxo complementa a poupança doméstica e permite uma elevação no investimento agregado. Adicionalmente, certos influxos de capital podem também gerar um spillover tecnológico, ao estarem associados a práticas administrativas e formas organizacionais mais avançadas. Os impactos indiretos decorrem de benefícios paralelos da globalização financeira, que envolvem o desenvolvimento do setor financeiro, melhorias no arcabouço institucional e melhores políticas macroeconômicas ${ }^{3}$. Por exemplo, Bartolini e Drazen (1997) argumentam que, ao assumir os custos de maior abertura financeira, um país estabelece um compromisso crível com melhores políticas macroeconômicas. Entretanto, um grupo de economistas tem questionado se estes impactos são realmente positivos. O argumento teórico decorre da ideia de políticas de second best, onde as distorções preexistentes de políticas macroeconômicas, do regime de comércio exterior, do mercado de trabalho e de assimetrias de informação, fazem com que os impactos da globalização econômica sejam diametralmente opostos aos esperados pela teoria convencional. Por exemplo, Brecher e Diaz Alejandro (1977) argumentam que se alguns setores forem protegidos com barreiras comerciais, com a liberalização financeira o capital estrangeiro pode entrar nestes setores para aproveitar os benefícios da proteção. Neste caso, haverá perdas de bem-estar associadas ao crescimento econômico (“immiserizing growth”). Adicionalmente, Stiglitz (2004) argumenta que a presença de informação assimétrica decorrente de falta de transparência em instituições financeiras pode levar a má alocação de capital estrangeiro quando da abertura financeira.

A evidência empírica sumarizada por Kose, Prasad, Rogoff e Wei (2010) sugere que não há uma relação robusta entre liberalização financeira e crescimento econômico pelo canal

3 Ver, por exemplo, Kose, Prasad e Terrones (2006). 
direto, como enfatizado pela teoria econômica convencional. Desta forma, esta evidência empírica é inconclusiva. Por outro lado, embora ainda esparsa, estudos empíricos parecem indicar que a relação entre liberalização financeira e crescimento econômico pelo canal indireto é positiva. Por exemplo, a integração financeira tende a disciplinar políticas macroeconômicas, pois países com maior grau de abertura financeira têm maior probabilidade de gerar melhores políticas monetárias, em termos de controle da inflação. Adicionalmente, Kaminsky e Schmukler (2003) argumentam que reformas institucionais ocorrem predominantemente após a integração financeira. Entretanto, não existe muita evidência de que a relação entre integração financeira e qualidade da política fiscal seja positiva. O motivo, argumenta-se, é que o acesso a financiamento externo permite que governos consigam sustentar maiores déficits por mais tempo, escapando das amarras do sistema financeiro doméstico. Finalmente, de acordo com Bonfiglioli (2008) e Kose, Prasad e Terrones (2009), a integração financeira parece impactar sobre crescimento econômico via deslocamento da produtividade total dos fatores, isto é, pela criação de ganhos de eficiência (por exemplo, a adoção de melhores tecnologias) e pela eliminação de distorções (por exemplo, com a melhoria das instituições financeiras domésticas).

Maior integração financeira tem sido apontada frequentemente como causa de maior volatilidade do produto e de crises financeiras. Kose, Prasad, Rogoff e Wei (2010) não encontram evidências sistemáticas entre abertura financeira e volatilidade do produto. No que diz respeito a crises financeiras, a evidência empírica parece indicar que países com controles de capital tendem a estar mais sujeitos a crises, embora isto pudesse simplesmente refletir o fato de que países com fundamentos macroeconômicos ruins adotam controles para se protegerem das crises. Adicionalmente, segundo estes autores, as evidências empíricas também não dão suporte à tese de que a liberalização da conta capital afeta positivamente a vulnerabilidade a crises bancárias, enquanto que os efeitos negativos de crises bancárias parecem ser menores em países com a conta capital aberta.

A liberalização financeira pode contribuir para aumentar os prospectos de crescimento econômico se for acompanhada de políticas macroeconômicas sólidas, que incluem as políticas fiscal, monetária e cambial. Cardarelli, Elekdag e Kose (2009) analisam as consequências das respostas de políticas macroeconômicas a mais de cem episódios de grandes influxos de capital em vários países ao longo dos últimos vinte anos. Episódios de grandes influxos de capital estão associados a apreciações cambiais, a deteriorações da conta corrente e acelerações do crescimento do produto, que tende a se reduzir significativamente após estes episódios. Com relação à política fiscal, eles concluem que manter gastos públicos sob controle durante episódios de grandes influxos de capital ajuda a evitar uma sobrevalorização excessiva da taxa de câmbio 
e a reduzir pressões de demanda agregada, levando a maior crescimento econômico após os episódios de grandes influxos de capital. Adicionalmente, resistência a apreciação cambial com esterilizações tende a ser ineficaz se o influxo for permanente. Finalmente, a introdução e aprofundamento de controles de capital não estão, em geral, associadas a melhores desempenhos macroeconômicos.

Com a globalização financeira, a escolha apropriada do regime cambial também é importante sob o ponto de vista de melhores resultados macroeconômicos. A abertura da conta capital conjugada com um regime de câmbio fixo pode tornar um país mais vulnerável a crises financeiras, levando ao colapso do regime de câmbio fixo, de acordo com Prasad, Rumbaugh e Wang (2005). Argumenta-se que na ausência de câmbio fixo, muitas das crises dos anos 1990, que envolveram o México, Ásia, Rússia e Brasil, poderiam ter tido efeitos menores ou mesmo terem sido inteiramente evitadas. Por outro lado, Husain, Moday e Rogoff (2005) encontram evidências de que câmbio fixo ou controlado pode ser vantajoso para países cuja abertura a movimentos de capitais é relativamente pequena. Adicionalmente, eles encontram que a probabilidade de crises financeiras é maior para países que têm câmbio fixo ou controlado. Neste sentido, Wyplosz (2004) sugere uma estratégia de curto prazo para países em desenvolvimento, baseada em uma combinação de um regime de câmbio administrado (soft peg) com limites bem desenhados sobre controles de capital. Tanto a manutenção de câmbio flutuante como a de câmbio fixo em uma situação de plena liberalização financeira requerem um forte compromisso com o estabelecimento de um bom arcabouço institucional, em particular no que diz respeito à regulação e supervisão do sistema financeiro.

Uma conclusão desta discussão é que os méritos relativos da globalização financeira dependem de fatores específicos de cada país. Conquanto o sistema financeiro doméstico for subdesenvolvido e houver a necessidade de evitar uma excessiva apreciação cambial decorrente dos influxos de capital, certos tipos de controles de capital podem ser utilizados, embora com a devida cautela. O problema desta estratégia é que a abertura financeira pode ser necessária para estimular o desenvolvimento do sistema financeiro doméstico e capturar os benefícios em termos de maiores possibilidades de crescimento econômico que os influxos de capital proveem.

\section{UMA AVALIAÇÃO DE CONTROLES DE CAPITAL COMO INSTRUMENTO DE POLÍTICA}

Embora liberalização financeira tenha potencialmente grandes benefícios de longo prazo para o crescimento econômico, o problema é que grandes influxos de capital no curto prazo podem provocar transtornos de natureza macroeconômica. A questão então é como 
lidar com este problema de forma eficaz. Uma maneira é pela instituição de controles sobre a movimentação de capital. Conforme Magud e Rainhart (2007), existem "quatro medos" que motivam a implementação de controles de capital:

i) Medo de apreciação: com os influxos de capital está associada à apreciação da moeda doméstica, que reduz a competitividade da indústria exportadora doméstica em mercados globais. Para evitar a apreciação cambial, um método utilizado é a acumulação esterilizada de reservas internacionais. Entretanto, ao longo do tempo, a esterilização da acumulação de reservas se torna cada vez mais difícil, o que motiva a adoção de um método mais direto de intervenção.

ii) Medo de capital especulativo de curto prazo (“hot money”): para elaboradores de política econômica de países em desenvolvimento, uma entrada repentina de grande volume de fundos em um mercado doméstico pequeno pode provocar uma certa distensão neste mercado, distensão esta equivalente à provocada por uma saída repentina de capital. A desconfiança sobre a volatilidade do capital especulativo de curto prazo motiva a introdução de um imposto capaz de dissuadir a entrada de capital e reduzir os danos provocados pela sua saída.

iii) Medo de grandes influxos: um grande influxo de capitais pode provocar distensão no sistema financeiro doméstico, em particular quando alimenta bolhas em mercados de ativos ou encoraja tomada de risco por parte de intermediários financeiros domésticos. Neste caso, a imposição de um imposto é vista também como benéfica.

iv) Medo de perda de autonomia monetária: este medo decorre da existência da trindade impossível, que estabelece que não se pode obter simultaneamente câmbio fixo, autonomia monetária e livre movimentação de capitais. Se os elaboradores de política econômica entenderem como desejável uma certa flexibilidade de política monetária para alcançar determinados objetivos de política, então deve-se abdicar de algo. Na presença do medo de apreciação, parece natural abdicar da livre mobilidade de capitais.

Assim sendo, a imposição de controles de capital parece ser útil para controlar pressões sobre a taxa de câmbio, evitar grandes influxos de capital e restabelecer a autonomia da po- 
lítica monetária. Entretanto, a evidência empírica é inconclusiva no que diz respeito ao alcance dos objetivos que levam à imposição de controles de capitais. Abdelal e Alfaro (2003) concluem que raramente países conseguem controlar fluxos de capital impondo controles, enquanto que Magud e Rainhart (2007) sumarizam a evidência empírica da seguinte forma: i) controles de capitais sobre influxos parecem tornar a política monetária mais independente, alterar a composição dos fluxos e reduzir a pressão cambial; ii) controles sobre influxos não parecem reduzir o volume de fluxos líquidos e, portanto, não conseguem influenciar o saldo em conta corrente; e iii) controles sobre saída de capital parecem ter tido efeito na redução do fluxo de saída apenas na experiência da Malásia. Desta forma, com a exceção da Malásia, não existe evidência sistemática de sucesso na imposição de controles. Em adição a estas evidências, Cardarelli, Elekdag e Kose (2009) encontraram que episódios de grandes influxos que terminaram com uma reversão abrupta do fluxo de capitais não parecem estar associados a menores controles de capitais.

Por outro lado, Forbes (2005) faz uma resenha de estudos recentes que usam dados microeconômicos e conclui que controles resultam em custos significativos de eficiência no nível de firmas individuais ou setores. Estes custos se referem a aumentos no custo do capital, redução na disciplina de mercado, criação de distorções no comportamento de firmas e indivíduos e imposição de custos administrativos substanciais ao governo. Desta forma, a evidência empírica disponível sugere que a imposição de controles de capitais não leve a significativos ganhos de performance macroeconômica, embora esteja associada a custos microeconômicos substanciais.

A despeito destes impactos esperados dos controles de capitais, persiste a questão de como lidar de forma eficaz com grandes influxos de capital, que têm o potencial de provocar instabilidade macroeconômica. Os instrumentos disponíveis para lidar com este problema são as políticas fiscal, monetária e cambial, intervenções no mercado de câmbio, regulação prudencial do sistema financeiro doméstico e eventualmente controles sobre capitais, que podem se tornar desejáveis em casos particulares. De acordo com Ostry et al. (2010), a combinação apropriada de políticas depende do estado da economia (quão próxima ela está do seu potencial), do nível de reservas internacionais (se é adequada ou se um nível maior é desejável ou apropriado), da qualidade da regulação prudencial existente (se a regulação existente do sistema financeiro é adequada para lidar com ciclos de crédito e bolhas de preços de ativos), da atual taxa real de câmbio (se é desejável deixá-la valorizar mais) e da persistência provável dos influxos de capitais (se forem permanentes, respostas de política são menos desejáveis do que se forem transitórios). Desta forma, controles de capitais são justificáveis como parte dos instrumentos de política econômica quando a economia estiver operando perto do seu potencial, o nível de 
reservas internacionais for adequado, a taxa real de câmbio não estiver depreciada e os fluxos de capitais forem considerados temporários.

Mesmo em se considerando a desejabilidade de controles de capitais nestes casos especiais, Ostry et al. (2010) ainda sugerem cautela quanto ao uso amplo de controles por parte de economias de mercados emergentes, por causa de consequências multilaterais adversas. Os autores advertem que a atual recuperação econômica global depende do ajuste macroeconômico das economias de mercados emergentes, que pode ser negativamente afetada por controles de capitais, particularmente em casos onde a taxa real de câmbio encontra-se depreciada. Não apenas a ampla adoção de controles de capitais pode aumentar os desequilíbrios globais e reduzir a velocidade de reformas econômicas necessárias, como também a adoção de controles por parte de alguns países pode levar outros a adotá-los, tendo um impacto negativo de longo prazo sobre crescimento econômico, integração e globalização financeira, com perdas significativas de bem-estar.

\section{CONCLUSÕES}

Globalização financeira e fluxos de capitais são uma parte importante do atual sistema econômico global e a questão importante é como estimular seus aspectos positivos ao mesmo tempo em que se minimizam seus aspectos negativos. O fato é que não existe uma forma absolutamente segura de lidar com influxos de capital de curto prazo que podem ter impactos desestabilizantes. Desta forma, a análise desenvolvida nesta nota considera que controles de capitais, mesmo que em situações restritivas, podem ser considerados parte integrante do conjunto de políticas macroeconômicas disponíveis para lidar com o potencial desestabilizante de influxos de curto prazo.

\section{REFERÊNCIAS}

ABDELAL, R.; ALFARO, L. Capital and control: lessons from Malaysia. Challenge, v. 46, n. 4, July-August 2003.

BARTOLINI, L.; DRAZEN, A. Capital-account liberalization as a signal. American Economic Review, v. 87, n. 1, p. 138-154, March 1997.

BONFIGLIOLI, A. Financial integration, productivity and capital accumulation. Journal of International Economics, v. 76, n. 2, p. 337-355, December 2008.

BRECHER, R. A.; DIAZ-ALEJANDRO, C. F. Tariffs, foreign capital, and immiserizing growth. Journal of International Economics, v. 7, n. 4, p. 317-322, November 1977.

CARDARELLI, R.; ELEKDAG, S.; KOSE, M. A. Capital inflows: macroeconomic implications and policy responses. IMF Working Paper, n. 09/100, May 2009. 
DAVIES, H.; DREXLER, M. Financial development, capital flows, and capital controls. In: The Financial Development Report 2010. Geneva: World Economic Forum, 2010. p. 3148.

FISCHER, S. Capital account liberalization and the role of the IMF. In: Should the IMF pursue capital-account convertibility? Princeton Essays in International Finance, Princeton, n. 207, p. 1-10, 1998.

FORBES, K. The microeconomic evidence on capital controls: no free lunch. NBER Working Papers, n. 11372. Cambridge, Massachusetts: NBER, 2005.

HUSAIN, A.; MODAY, A.; ROGOFF, K. Exchange rate regime durability and performance in development versus advanced economies. Journal of Monetary Economics, v. 52, n. 1, p. 35-64, January 2005.

KAMINSKY, G. L.; SCHMUKLER, S. Short-run pain, long-run gain: the effects of financial liberalization. NBER Working Papers, n. 9787. Cambridge, Massachusetts: NBER, 2003.

KOSE, M.; PRASAD, E.; ROGOFF, K.; WEI, S.-J. Financial globalization and economic policies. In: RODRIK, D.; ROSENZWEIG, M. (Ed.) Handbook of Development Economics. v. 5. Amsterdã: Elsevier, 2010.

KOSE, M.; PRASAD, E.; TERRONES, M. Does openness to international capital flows raise productivity growth? Journal of International Money and Finance, Amsterdã, v. 28, n. 4, p. 554-580, June 2009.

KOSE, M., PRASAD, E.; TERRONES, M. How do trade and financial integration affect the relationship between growth and volatility? Journal of International Economics, Amsterdã, v. 28, n. 4 , p. 554-580, 2009.

MAGUD, N.; REINHART, C. Capital controls: an evaluation. In: EDWARDS, S. (Ed.) Capital controls and capital flows in emerging economies: policies, practices, and consequences. NBER Conference Report. Chicago: University of Chicago Press, 2007.

OSTRY, J. et al. Capital inflows: the role of controls. IMF Staff Position Notes, n. 10/04, 2010.

PRASAD, E.; RUMBAUGH, T.; WANG, Q. Putting the cart before the hore? Capital account liberalization and exchange rate flexibility in China. IMF Discussion Paper, n. 05/1. Washington: IMF, 2005.

RODRICK, D. Who needs capital-account convertibility? In: Should the IMF porsue capital-account convertibility? Princeton Essays on International Finance, Priceton, n. 207, p. 55-65, 1998.

STIGLITZ, J. Globalization and its discontents. Nova Iorque: W. W. Norton \& Company, 2002.

STIGLITZ, J. Capital-market liberalization, globalization, and the IMF. Oxford Review of Economic Policy, v. 20, n. 1, p. 57-71, 2004.

SUMMERS, L. International financial crises: causes, prevention, and cures. The American Economic Review, v. 90, n. 2, p. 1-16, May 2000.

WYPLOSZ, C. Financial instability in emerging countries: causes and remedies. In: FORUM ON DEBT AND DEVELOPMENT (FONDAD) CONFERENCE, Chile, 2004. 
